\title{
Selective Memories, Sanitised Futures: Constructing Visions of Future Place in Sydney
}

\author{
Glen Searle and Jason Byrne
}

\begin{abstract}
The contemporary remaking of inner city Pyrmont - Ultimo in Sydney is analysed in terms of the visions of planners, developers, politicians and residents. Developers and government agencies selectively remembered the blue-collar history of this place in their place marketing efforts. These "memories" were sanitised to make them more appealing to contemporary lifestyle-oriented residential markets. The need to sanitise and repackage particular urban places can be regarded, following Bourdieu, as a strategy of the field of planners and developers, as they struggle to gain ascendency in the game of land and property development. Their "feel for the game", it is argued, is reflective of a "planning habitus".
\end{abstract}

\section{Introduction}

This paper analyses the way in which particular visions of future Pyrmont - Ultimo in inner Sydney became the basis of a major redevelopment scheme for this area. It tells the story Pyrmont-Ultimo as a former industrial area, close to central business district, and its transition to an upmarket residential locale. Characterised by brick buildings, rail yards, an eclectic mix of industries and an equally eclectic residential population, memories of this place have evoked mixed emotions on the part of residents. Characteristically, these memories conjure up grit, grime, smoke and noise but also diversity, liveliness and above all a sense of vibrant community. The contemporary remaking and imageering (Kearns and Philo, 1993) of Pyrmont-Ultimo is a radical departure from the past.

Memories upon which the development is centred have been selective, ignoring much of the industrial and working class history of the suburb. The new development conveniently overlooks conflicts, residents' expectations and the former "sense of place" derived from the built form, landscape elements and residents' memories of the place. This was not accidental, but rather represents an effort on the part of "place entrepreneurs" (Davis, 1992; Logan and Molotch, 1987; Holcomb, 1993; Lowe, 1993) to "repackage" (Philo and Kearns, 1993) and sell a particular vision of Pyrmont - Ultimo. The industrial and ethnic working-class landscape was literally "white-washed" with a new patina of technology and middle-class lifestyles, as planners and developers, in their role as place entrepreneurs, sought to simultaneously erase competing representations of the place and legitimise the new development, by deploying their own particular images, themselves designed to connote a new sense of place (Cosgrove, 2000). In many ways, this practice is perhaps indicative of a planning habitus, where the values, norms, beliefs and rules of planning are transmitted to planners through pedagogy and praxis, reflecting a socially constructed and historically constituted culture of planning.

In the paper, we seek to answer several questions:

- What were the visions of those in authority responsible for framing the redevelopment schemes for Pyrmont - Ultimo?

- $\quad$ Did these visions draw on a sense of place emanating from this area or on a notion of future urban space derived from images that are more appropriate to the sense of place of other cities, and different places?

- Did this development succeed, in any way, to encompass a continuity of the previously existing sense of place for residents or did the project attempt to replace it with an officially sanctioned new (constructed) sense of place?

The paper examines, in each instance, the extent to which the sense of place of the local residents was incorporated into the redevelopment proposal, and the extent to which the new urban areas in the proposal were locally contested. 
The paper is structured into three broad sections. The first briefly examines the notions of "the habitus" and "sense of place" as they apply to the redevelopment of ex-industrial sites like Pyrmont Ultimo. The second section is comprised of a discussion of the Pyrmont - Ultimo case study. The final section seeks a synthesis by drawing together common themes and reflecting on local and global trends in the reuse of ex-industrial, inner city sites, and the role of the habitus of planners, as active participants in place marketing.

\section{Habitus}

The habitus is, according to Bourdieu (1984: 468-469) an historically constituted, shared generative schema of perception, appreciation and categorisation, mediating between structure and agency (Nash, 1999), and / or connect[ing] structure and agency in a dialectical relationship (Hillier, 2001: 2) which enables the (re)production of social practices by an individual with a social group. It takes the form of "embodied social structures [or]...practical knowledge of ...social world[s]" which are “...the product of the...division into classes (age groups, genders, social classes) and which function below the level of consciousness and discourse." (Bourdieu, 1984: 468-469). The habitus serves to transmit and "embed" attitudes, values, norms and beliefs of the social group or "social world” within an individual, during the course of socialisation, as the individual practices those activities normally associated with such attitudes, values, norms and beliefs.

In a sense, the habitus is the "... art of behaving with persons and things that have and give "class"” (Bourdieu, 1984: 472). According to Bourdieu (1984: 170), [t]he habitus is necessarily internalised and converted into a disposition that generates meaningful practices and meaning-giving perceptions, it is a general, transposable disposition which carries out a systematic, universal application...”. Stephens (1997) notes that "...the habitus is not a natural space..." rather it is "...a social space that is apprehended through mental structures...”. It is a mechanism that both produces social practices and enables the reproduction of social practices (Stephens, 1997). Butler, $(1999,117)$ notes that the habitus is "built up" through "... a feeling for how to operate within the established norms of the social field." According to Butler, "...the habitus is itself formed through the mimetic and participatory acting in accord with the objective field.” Thus, in learning to emulate a way of being and doing which seems right, through practice - essentially effecting a way of being and doing; one embodies that particular way of being, doing and perceiving, and in the process, differentiates / distanciates oneself from others who adopt different ways of being and doing. Citing Bourdieu, Stephens (1997) picks up this point, noting that “...the habitus implies 'a sense of ones place' but also a 'sense of the others place' within a cultural system. The habitus thus regulates both individual and group / collective practices. Furthermore, “...different conditions of existence produce different habitus” (Bourdieu, 1984: 170). Thus, proclivities develop for particular tastes, actions, etc. that in turn reinforce the habitus, and maintain the existing social order.

There are two other important concepts for understanding habitus. These are notions of "the field" and "a feel for the game". Wallace and Wolf (1995) and Hillier (2001b: 4) provide an excellent coverage of these concepts, and for the sake of brevity, we shall only briefly outline them here. A field is “...the socially structured space within which actors struggle” to achieve their objectives (Hillier, 2001b: 4). Wallace and Wolf (1995: 134 - 135) similarly define a field as “...a social arena in which, just as in a game, people maneuver, (sic) develop strategies, and struggle over desired resources.” Thus a field is a domain of contestation. The notion of a 'feel for the game' on the other hand, refers to “...not just understanding and following the rules" but also having an "...awareness of and responsiveness to the play of all of the actors involved” (Hillier, 2001b: 4). A feel for the game, according to Hillier, comes with experience. For example, it would enable one to know when it is all right to break the rules. It would also enable one to tell “... what is possible and what is not” (Hillier, 2001b: 4). A feel for the game is related to the position of an actor within the field and is dependent upon that actor's "viewpoint of the field" (Hillier, 2001b: 4).

Finally, an important element of the habitus for understanding the ways that planners might unconsciously act to perpetuate a habitus is that “...types of behaviour can be directed towards certain ends without being consciously directed to these ends, or determining them.” (Bouveresse, 1999: 52 citing Bourdieu). Nash (1999: 176) offers some additional and important insights that round out the notion of habitus. He argues that "...habitus has a history and discloses the traces of its origins in practice." Further, according to Nash, "[t]he structural code of the culture is inscribed as the habitus 
and generates the production of social practice” which in turn "...may then be analysed to reveal the nature of the habitus."

The notion of habitus is central to understanding the contested spaces of Pyrmont-Ultimo as both a site of production and consumption. Indeed, Bourdieu (1984: 483) asserts that a “...class is defined as much by its being perceived as by its being, by its consumption - which need not be conspicuous in order to be symbolic - as much by its position in the relations of production..." (italics in the original). Thus, the habitus is a social space, and in the transmission of habitus, one gets a feel for both one's place and the place of others in that particular social space. What about physical space though? Could it be that it too is inscribed by the cartography of contestations between groups over their habituses? Is it possible that the habitus could also be linked to the geographical notion of place or perhaps more appropriately a 'sense of place', especially if that sense of place connotes a differentiation between / within a social group? These are questions to which we now turn.

\section{Sense of Place}

Cosgrove (2000: 731-734) documents the development of the concept of sense of place within geography. According to Cosgrove, sense of place is derived from the intrinsic character of a place and feelings or sentiments of attachment (or detachment) that people experience for that place. These sentiments may arise in response to the physical qualities of a place - such as inspiring topography or to cultural qualities - significant events that have left the place haunted by meanings and / or memories, for example sites of tragedy or conflict (Cosgrove, 2000: 732). In essence, a sense of place is the (dis)connectedness that human beings feel for a particular locale. Cosgrove states that the most commonly studied aspect of sense of place has been "the experience of 'home'...where one feels oneself 'in one's place'.”

Considering sense of place in the changing nature of Westchester county - New York State, Robert Chapman (1999: 81) remarked that returning to a street from his childhood, he found it markedly changed. He said that "the transformation" left him "feeling like a stranger - an alien", in essence, displaced. Chapman (1999: 82) recounts how his maternal grandmother used to tell him stories about landmarks in the suburb, and he asserts that the place of his childhood "was the embodiment of a way of life." He (1999: 83) further asserts that the "contours of a place exist in the mind..." and that the loss of identification with particular aspects of places leads to "placelessness". Chapman (1999: 86) bemoans the coming of malls, McDonalds and mass consumption to Westchester County. He feels that Westchester "is not a place - it is no place. Westchester exists in 'McWorld'." For Chapman, Westchester had become a simulacrum. It "could exist anywhere in the world; it has no vital connection to a certain locale, a definite place.”

Harvey (2000, 209), argues that: “...people perceive their common identity through such devices as tradition and custom, by recourse to a 'contextually determined ethical disposition' or habitus. ....it is the recourse to a familiar landscape of experience that allows the unchallenged transmission of social memory...”. In her recent article on "Connected Cities”, Healey (2000: 56) similarly notes that: “...in the paradoxical complexity of contemporary urban life, places can exercise a force of their own. As people move around, they build associations with particular places, giving meanings to them as they give identity to themselves.” Harvey (2000: 208-209) also recognizes this connection. Drawing upon the concept of habitus, he asserts that landscapes are "...bound up with the generation of identity and a particular version of the past. ....In other words, the idea of landscape is implicitly related to notions of identity, experience, familiarity, continuity and tradition". The "sense of place" felt by Chapman is important in understanding how individuals attribute meaning to places and in turn how places shape their identities. It is also important for an understanding of the ways in which places function as repositories of social meaning, and are imbued with cultural histories.

Habitus may thus be considered to be an "embodied as well as a cognitive sense of place” (Hillier, 2001b: 2), and since as Cosgrove (2000: 733), reflecting Healey, asserts "[i]n the contemporary context [senses of place may be] mobile, flexible and contingent”, we may also conjecture that the habitus is also somewhat malleable and permeable. Cosgrove (2000: 735) asserts that various agencies do indeed “....seek to fix and control place meanings and identity, and thus materialize and 'official' sense of place. What then are the consequences, when meanings of place are to some extent fabricated by "place-makers" - the developers and planners who determine the nature of the built form? To what 
extent do these 'intentionally-shaped' places 'select for' new residents - particular types of people, with proclivities towards residing in such places? How do place entrepreneurs appeal to a sense of place in order to market their projects? The following section begins to address these questions before seguing into a more detailed analysis through a discussion of Pyrmont-Ultimo.

\section{The Habitus and inner city sense of place}

In her study of the habitus of 'loft living' in inner city Montreal, Podmore $(1998,283)$ recognized not only “...the role of culture in structuring inner city landscapes" but also the importance of "symbolic systems of imagery...in the practice of aesthetics, social locations and lifestyle.” This is important for several reasons. First, Podmore asserts that reproducing New York's SoHo district in Montreal was more than "...simply copying the aesthetic of SoHo as a redevelopment strategy" (Podmore: 1998, 284). It was also a means of coding the landscape with a very particular set of meanings, to attract those with a disposition for 'loft living' as an aesthetic and class-based lifestyle, in keeping with the habitus of elite inner city living. Second, it reaffirms the connection between habitus and sense of place, through resident's affiliation to both landscape and architectural forms. Third, Podmore also seems to suggest the possibility that place entrepreneurs may share a habitus of their own, which shapes their actions in their attempts to "revalorise...the inner city". Indeed, she states that:

\footnotetext{
"[b]ecause of the contingent relationship between the economy and the 'locale' we need to understand the 'SoHo Syndrome' as more than a universal revalorisation strategy: it is a socio-cultural process that involves a complex web of relationships between place, identity and the media, that is diffused to, and (re)produced in, divergent inner-city locations."
}

Podmore draws upon Bourdieu's understanding of taste and lifestyle as vectors of transmission of both class identity and appropriate practices of individuals socialized into a particular class, to discuss a habitus of inner city living.

According to Podmore (1998, 286), “[t]aste and lifestyle are part of the practice of distinction between and among social groups that work to construct identification and participation in a clearly defined habitus.” Citing Bourdieu (1984), Podmore continues “...taste and lifestyle have a much more complex relationship to space, history, class, consumption, practice and the material environment. Tastes and lifestyles are actively constructed through a recursive relationship between social agents and 'system(s) of classified and classifying practices." " Significantly, meanings are shared between agents in a defined field, about what it means to live in the inner city, including sharing a cosmopolitan lifestyle, pioneering new urban spaces and being part of a broader global pattern of consumption associated with a particular social group (Podmore, 1998: 288). Planners play an important role as change-agents in recoding the landscape to sustain these new meanings. They are both actants, embodying a habitus in the built form, and simultaneously are acted upon by that habitus. Hillier (2001b: 2) supports the assertion of a habitus of praxis in planning, and argues that this notion can be used to develop a "political economy of practice".

As both physical and social space, Pyrmont-Ultimo is a good example of the influence of place in mediating meaning. It can be regarded as the site of multiple and competing habituses. The elitist habitus of planners and developers leads them to view the space as open to redevelopment in a way that will reinvigorate the city, whereas the habitus of existing residents leads them to resist redevelopment, in the hope of preserving their sense of place. Following the above mentioned cues from Cosgrove, Healey and Chapman, we ask "what kind of place is Pyrmont-Ultimo", "how was it constructed”, "for whom does it exist as an identifiable space with a distinct sense of place", "how does it function as a site of cultural transmission", and "whose culture is ultimately represented in this place”?

\section{Pyrmont-Ultimo - harbourside for sale}

The peninsula of Pyrmont-Ultimo tumbles into one of the world's most beautiful harbours at its economic centre next to the CBD of Sydney. This location has meant that Pyrmont-Ultimo has been intensively remade several times in its history as new rounds of opportunity to profit from the harbour have generated successive waves of new development. The latest development round, extending from the 1990s, has seen the peninsula reconstructed as a site for gentrified inner city living and working, all but obliterating the structures of its industrial past. As in previous cycles of development, the latest 
rebuilding has also obliterated existing communities and their hopes and visions for their area. As Fitzgerald and Golder (1994, p. 128) have concluded:

"Against the onslaught of powerful industries, of constant erosion of amenities, constant discounting of human values, the fabric of community has been torn to shreds again and again.”

Twenty years ago most Sydney residents would have only known Pyrmont as the first area they passed through on their way west out of the city, being aware of the looming presence of the old power station on their right as they drove or bussed their way up the rise from old Pyrmont Bridge. Some would have looked across Darling Harbour from the western slope of the city and observed a jumble of rail yards, dockside sheds and nondescript industrial buildings. Further north, towards the Pyrmont end, the graceful 1920s public housing of Ways Terrace marked the line of the ridge beyond the power station. Standing on the ridge itself, the harbour and its shores filled the scene, the shoreline twisting away in all directions, with the Harbour Bridge arching away from the city building cluster in mid distance, bounding the ships and boats using the wharves of Pyrmont and other harbour shores.

Below were finger wharves and their sheds and the grand tall red brick Navy building from a more optimistic time, all extending out from the distinctive sandstone cliff characteristic of the harbour's peninsulas and prominences. Behind this viewing point was a mixture of decaying nineteenth century terrace housing, a gaggle of large brick buildings comprising the CSR sugar refinery extending back from the northern waterfront, and empty weed-grown areas where old redevelopment schemes had only progressed to demolition stage. Most of all, it was the special Sydney combination of sandstone, ridge, and surrounding harbour that would have excited the viewer. It would be this special combination, located as it was next to the city centre, which would fuel the intense redevelopment of the 1990s.

\section{The process of contemporary Pyrmont-Ultimo redevelopment}

The contemporary redevelopment of Pyrmont-Ultimo started in 1988, when a Central Sydney Strategy of the State government and Sydney City Council had identified the peninsula's development potential as warranting a separate strategy. The new Liberal-National State government's policy of selling surplus government land to reduce State debt payments gave such a strategy a new urgency. Pyrmont contained a number of major government sites that had (or soon were to) become surplus, such as old port lands, an old power station site, and the government printing works building. Redevelopment of these sites could generate funds and, together with redevelopment of increasingly obsolete industrial sites on the peninsula such as the wool stores, could significantly help the government's main urban policy, urban consolidation, as well as relieve the late 1980s boom-time pressure on central city office accommodation (see Berry and Huxley 1992, for an alternative analysis).

The government, with input from the city council, commenced work on a City West regional strategy for the peninsula and other inner west areas with large surplus government land holdings. A draft City West Regional Environmental Plan (REP) to provide for a large increase in population and jobs was exhibited in 1991 and was adopted (gazetted) in 1992. In the same year the Commonwealth government signed an agreement with the state government to provide it with $\$ 117 \mathrm{~m}$ of Building Better Cities funds to assist in infrastructure provision for redevelopment. An Urban Development Plan setting out development controls for Pyrmont and Ultimo was gazetted in 1993 (see Hillier and Searle (1994) for a full planning chronology).

To facilitate redevelopment of Pyrmont-Ultimo - essentially, to 'fast track' development - the REP contained several key measures. It rezoned the area for redevelopment, thus bypassing the normal local council powers to do this. It further dictated development principles that the council or the Minister for Planning was required to consider before allowing development. Next, the REP introduced the UDP, which would replace the standard local government development controls under the Environmental Planning and Assessment Act. Finally, the REP provided for Master Plans. These would apply to key sites in Pyrmont-Ultimo mainly located on the waterfront, and provide details of the preferred type of development there. The Minister for Planning would be the consent authority for development in Master Plan areas, thus removing developer uncertainty about local government approval. Moreover, the REP allowed Master Plans to be prepared by owners or lessees of sites, giving owners/developers a high degree of potential control over their development. 
The new plans and planning procedures for Pyrmont-Ultimo were accompanied by the setting up of the City West Development Corporation (Hillier and Searle, 1994). The Corporation, staffed by the government's Property Services Group and set up under 1970s growth centres legislation, became the development agency for the peninsula. Its major responsibilities were to be the administration of government sites and the provision of major infrastructure, as well as the general implementation of the redevelopment plans, which included responsibility for public participation programs.

Thus Pyrmont-Ultimo's redevelopment was to be almost total, facilitated by government-controlled development rules which gave significant control to large landowners, by major infrastructure funding from the state and Commonwealth governments, and by a specially created development corporation to co-ordinate and speed the whole process. Pyrmont-Ultimo's redevelopment has been shaped by a vision which, although contested, was produced out of competing interests of differing habituses and power.

\section{The government's development vision}

The State government's vision for Pyrmont-Ultimo to be redeveloped as a high density residential and employment zone was clear from the start. At first this vision seemed to involve reconstruction at the scale of inner Paris or Berlin. The initial planning document showed indicative building heights of 3 to 6 storeys over nearly all of Pyrmont and of 5 to 7 storeys over most of Ultimo (Department of Planning, 1990). The following year another planning document saw the area becoming 'a mediumrise, high density community that combines the technological advantages and expectations of the twenty first century with human needs and the vitality of inner city living' (Travis Partners, 1991, p. 4). The artist's impression accompanying this vision showed a mixture of medium and high density development, mostly at 6 to 8 storeys with heights rising up to 12 storeys near the waterfront. At the same time, Pyrmont-Ultimo would somehow have a 'human scale' with a mix of uses, new park and foreshore areas, major infrastructure works and a light rail transport system (Travis Partners, 1991, p.4). The overall conception was of an 'urban village'. It was intended that urban design principles would reinforce the 'special characteristics' of Pyrmont-Ultimo and conserve the heritage character of the area. From the start, this vision of a contextualised urban village development looked hard to achieve in the face of the massive intended increases in jobs and population

The initial draft regional plan that followed intended that the population would increase to 16,500 (from a level of 2,800 in 1986), and employment would increase from 14,000 to 54,000, complementing CBD activities (Department of Planning, 1990; Brian Elton and Associates, 1991). The peninsula's redevelopment would be a major contributor to the government's prime urban planning policy, urban consolidation, which the neo-liberal state government elected in 1988 was pushing hard to save on government infrastructure spending. The state's centralisation of planning processes to achieve consolidation in Pyrmont-Ultimo was to be merely the most extreme example of a range of government consolidation policies for Sydney overriding local government's planning and development control powers. The high employment target reflected the perceived attraction of the area for CBD-related activities as Sydney's global role expanded after Australian financial deregulation, combined with land prices significantly lower than those in the city which had rapidly inflated in the asset boom of the late 1980s. After the office market crashed in the early 90s and inner city living took off as a Generation X lifestyle option, the targets were revised. The future population was increased to 20,000 and future employment reduced to 40,000 (City West Development Corporation, 1998).

Infrastructure costs would be met by proceeds from the sale of government land on the peninsula. This was to compromise the government's attitude to development on its own sites. Maximising the scale of that development would be imperative to produce the high financial returns needed to fund the infrastructure required for such a major expansion of housing and jobs. In theory this need to squeeze development on to government land would be reduced when the Commonwealth government offered Better Cities money for infrastructure in 1992, but no reduction of development densities on state sites was made as a result.

The ambitious population and employment targets brought a ratcheting up of the physical scale of development. The draft regional plan showed over half the peninsula with 10 storey maximum heights, rising up to 25 storeys at six 'landmark' sites (mainly government-owned) (Department of Planning, 1991). Moreover, under the operation of the master plan process, these maxima were to become mere starting points for developers in negotiating with the Development Corporation. Today, the old sugar 
refinery site has residential towers rising to some 20 storeys at a location where the draft plan showed the 'predominant parapet heights' as being 5 to 10 storeys. Like many of the other new apartment buildings, they have no discernible design features connecting them to Pyrmont's 'special characteristics': the towers look as if they have been displaced from a tropical resort, with sides a jumble of jutting balconies to maximise views.

\section{Pyrmont as a media/IT centre}

Early planning for the peninsula envisaged 'an advanced technology-based community with world class telecommunications infrastructure' for living and working (Travis Partners, 1991, p. 4). This vision, and the area's proximity to the city, have seen Pyrmont-Ultimo become a focus of media and telecommunications. Four television corporation headquarters have located there, along with national head offices of Murdoch Magazines and Nokia telecommunications and a major film production company. This development is an apt symbol of Pyrmont's passing from an old industrial economy to a structure based on new economy jobs on the peninsula and in the city.

\section{Keeping it the same - the community vision}

The contemporary redevelopment of Pyrmont-Ultimo has been opposed by most of the existing community from the start. Throughout, its vision for the area has been a defensive one; of trying to turn back enough of the tide of development to preserve the existing way of life and its physical associations. Back in the early 1980s, the huge scale of Darling Harbour redevelopment and its potentially serious traffic and redevelopment impacts on the rest of the peninsula led to the formation of the Ultimo-Pyrmont Residents Opposed to Arbitrary Redevelopment group (Fitzgerald and Goldner, 1994, p. 116).

The City West plans for the development of the whole peninsula brought a generally hostile community response (Hillier and Searle, 1995). Towards the start of the planning process, the Australia Council funded a cultural mapping exercise - the 'Pyrmont Pieces' project - in which the community mapped items in Pyrmont it considered important. To a local community worker, this project gave a community vision for the suburb (King and Cavadini, 1994). The mapping brought out a range of items that 'had a lot to do with people's memories and how these were attached to the environment' (King and Cavadini, 1994). The sixty items ranged from large structures such as the railway cutting, which bisected Pyrmont, and the wharves to small features such as steps cut out of stone and fig and palm trees. The subsequent regional plan listed 106 heritage items in Pyrmont and Ultimo combined, but only 13 of these covered Pyrmont Pieces items. The continuing existence of the other 47 items valued by the community would be at the mercy of the profit and loss calculations of developers.

As the scale of the redevelopment proposals became clearer and the destruction of much of old Pyrmont got under way, the community became more vociferous. Residents told of their wish to preserve Pyrmont's sense of close-knit community where families looked after one another and 'everyone was accepted' (resident, in King and Cavadini, 1994). A community activist said he felt a sense of duty to pass on a Pyrmont that was 'undamaged' to the next generation of residents (King and Cavadini, 1994). At a community workshop held in June 1991, residents expressed fears that tall buildings would cause the area to lose its character as well as cause loss of views, overshadowing, and loss of privacy (Brian Elton and Associates, 1991, p. 38). When the draft regional plan came out, residents saw its proposed landscape of high buildings as 'vandalism' and an 'absolute' denial of Pyrmont's uniqueness' (resident, in King and Cavadini, 1994). In short, Pyrmont's redevelopment was being planned 'as though the peninsula were empty - terra nullius' (O’Brien, 1994).

There was widespread community agreement that keeping the character of Pyrmont in the face of redevelopment required, in particular, the keeping of existing housing and maintaining the heritage character of the area (Brian Elton and Associates, 1991, p. 35). The focus of this fight was a key group of early nineteenth century cottages in Scott Street, which had been occupied by squatters for twenty years. To the community they represented the history of Pyrmont's working class people as well as its architecture, and had been the subject of an iconic post-war painting by Sali Herman. The regional plan had earmarked them for demolition as part of an eight to ten storey zone. But this group, and several other old houses also slated for demolition, were ultimately listed in the plans as heritage items and 
saved. The community's resistance was crucial to this outcome, typified in the angry comments made at one City West community liaison meeting about the failure of plan proposals to protect the Scott Street houses (King and Cavadini, 1994). But community protests did not save all old houses: for example, residential terraces were demolished in Murray Street and redeveloped for ten storey apartment buildings as allowed by the plan (SMH 9 July 1996).

The more general issue, which the community faced here, was that the regional plan proposed dense development across the whole peninsula. This was seen as threatening existing residential cohesion and making it virtually impossible to keep Pyrmont's essential virtue of people 'living in strong harmony’ (activist/architect, in King and Cavadini, 1994). Existing housing was concentrated along the centre of the peninsula. A community activist and architect, recognising the reality of the government's development juggernaut with its 15,000 population target, produced an alternative plan to house this population which would keep the centre as it was, especially around the disputed Scott Street heritage area. Under this plan, the large-scale 'monumental' buildings would be built around the edge on the water (King and Cavadini, 1994). The activist claimed success in getting the final regional plan altered in this direction, using his own knowledge of government decision-making processes to make this happen (Hillier and Searle, 1995). Nevertheless this essentially just reshuffled new development; the overall scale of Pyrmont-Ultimo redevelopment and its population and job targets remained unaltered.

A second focus of community resistance to the Development Corporation's plans was about keeping local parks. In 1989, residents discovered that the part of the park from Ways Terrace down to the Harbour wharves - the James Watkinson Reserve - would be lost to a private housing development because the City Council's government-appointed commissioners had on-sold the land (Fitzgerald and Goldner, 1994, p. 123). The community was outraged and mounted pressure on the government to save the whole reserve (SMH 27 November 1990). When the Minister launched the regional plan in 1992 he announced that Watkinson Reserve would be returned, to which residents responded with a statement of 'gratitude' (Fitzgerald and Goldner, 1994, p. 126). Thus empowered, and perturbed by the general lack of green areas in the plan, the residents then proceeded to make their own park ('Interim Park') on unused land to the other side of Ways Terrace (SMH 1 March 1993). However the regional plan had earmarked the land for high-rise housing. Despite community protests including a public rally (SMH 11 May 1995; SMH 2 October 1995), the government approved the sale of the land to a developer (SMH 2 February 1996). Eventually the plan's intention for a showpiece park on Pyrmont Point would be realised, but this was still a small contribution in relation to the large proposed population increase (Searle, 1998).

But the main touchstone of community concern over redevelopment was the construction of Sydney's Casino on the old power station site. The original plans for Darling Harbour's redevelopment in the early 1980s had shown the site of the casino being on the city (eastern) side of Darling Harbour in a commercial area with few residents, unlike the Pyrmont side. When the Pyrmont power station was closed and its site became surplus, the government decided in 1993 to capitalise by requiring the casino to be built there instead. The wining casino partnership proposed a complex of three towers up to 19 levels with parking for 2,500 cars. Residents generally viewed the proposal with dismay, claiming it would block views and intensify pressures for higher density development in Pyrmont (King and Cavadini, 1994). The council supported the residents, reporting to the Minister for Planning that the casino's height, scale and intensity would detrimentally affect Pyrmont's residential amenity, contrary to the objectives of the regional plan (Searle and Bounds, 1999). Even though the casino was redesigned to a lower height, its scale remained unchanged. The threat of a challenge to its legality under the regional plan caused the government, fearing the delay of its $\$ 376$ million casino licence fee, to issue a state planning policy making it the approval body for development and allowing any inconsistency with the regional plan. The massive curving wall of the casino today dominates most views of Pyrmont.

Another area of major community concern with the government's plans was likely changes in the social composition of this traditionally working class suburb. The government's initial social impact assessment warned that new residents would 'predominantly be drawn from high and middle income groups, as a consequence of high land values and high housing costs' (Brian Elton and Associates, 1991, pp. 43-44). Residents expressed alarm at the prospect of redevelopment bringing hordes of 'yuppies' into the area (SMH 7 September 1992). Inevitably, the harbour views and the proximity to the booming central city job markets in finance and producer services meant that developers could 
maximise profits by building apartments for those same yuppies. So Pyrmont was marketed as offering the Good Life to the more affluent, with marketing targeted to 'empty nesters' and DINKS [dual income no kids] (City West Development Corporation, 1998). The Jackson's Landing development on the old sugar refinery site was advertised as offering 'luxury accommodation with opulent features', with a pool, sauna, spa, gym, and 'On Line Butler' shopping (SMH Domain 17 June 2000; Sun-Herald 18 June 2000). The habitué habitus that has animated the peninsula's new 'sense of place' is that of the new apartment dwellers, as interpreted by developers. The new residents have been drawn to a highrise lifestyle mixing city centre attractions and harbour views, a sense of place constructed because it also maximised the profits of developers.

As a result, Pyrmont's new dwellings are much less affordable than the Sydney average. By 1997/98, the median selling price of Pyrmont units was \$305,000 compared to overall Sydney medians of \$210,000 for units and \$243,000 for houses (Sydney Morning Herald Home Price Survey 1997/98). Long-term residents have borne the brunt of the large increases in rents that have followed, with some paying 70 percent of their income in rent (The Australian, 7 May 1996). To provide affordable housing, the regional plan was amended to require developers to build or fund via a levy, 200 'affordable' housing units. Whether even such units would be within reach of working class residents was debatable, as the plan amendment included households with incomes up to 120 per cent of the Sydney median income in the 'low to moderate' income households it was targeting. Another 400 affordable units are being developed using Better Cities funding and state government proceeds from land sales on the peninsula. The total of 600 units provided under the program will comprise around 8 per cent of total dwellings, a level about the same as Sydney's public housing average, but not enough to prevent a gentrified suburb from emerging.

There were some in the community who were not opposed to the peninsula's redevelopment. A small group of local business people supported the casino (King and Cavadini, 1994). Landlords objected to the retention of old housing, which would reduce their chances to profit from high land values (King and Cavadini, 1994). But such people were a definite minority in the community.

\section{The Green vision}

In 1991, Greenpeace won a national design ideas competition for new forms of housing. Its winning design was for car-free redevelopment of Pyrmont (Bell, 1993). Car parks were to be confined to the perimeter of the peninsula next to a light rail line linking Pyrmont to the city. This would give safe access to the waterfront:

$$
\begin{aligned}
& \text { "For even young children [this] offers the opportunity to explore the street as living } \\
& \text { space equal to private gardens, balconies, and public parks" (Bell, 1993, p. 14). }
\end{aligned}
$$

In Greenpeace's design, the most prominent parts of the peninsula were reserved for public parks, as not everyone could have a harbour view. Some areas were left as wilderness areas for 'adventure play' by children.

Most of the residential buildings would be no more than four storeys high to minimise lifts and maintain 'contact with the ground' (Bell, 1993, p. 14). Housing would be designed as flexible terraces and apartments in U-shaped blocks around central shared gardens. Upper level dwellings would have access to roof terraces to take advantage of Sydney's climate. A self-contained sewage treatment system would use micro-filtration technology to irrigate all green spaces with treated wastewater. There would be reuse of existing industrial buildings to the maximum extent possible.

Few of these ideas were taken up by the planners and developers. The light rail line was built but was not used to allow traffic-free zones. New housing was built to a norm of eight or nine storeys without gardens or accessible roof terraces. Harbourside land at Pyrmont Point was made into an expensive public park, but prominent sites above the point have been grabbed for apartments with expensive private harbour views. All of Greenpeace's proposals could have been implemented within a market framework as its scheme would still have produced land values above those of the old industrial uses. But the desire of both government and the development sector to maximize the amount of urban consolidation saw them effectively disregard the green vision. 


\section{Professional wisdom}

The government's evolving planning framework for the peninsula's redevelopment was paralleled by an on-going critique from council planners, architects and expert newspaper commentators. This was supported by a series of critical general stories in the influential daily Sydney Morning Herald, which had increasingly seized on local anti-development issues as one means of cementing reader loyalty. This critique has consistently criticised the scale of new Pyrmont development and its unsympathetic relationship to existing housing in particular. Early on, noted architectural critic E. M. Farrelly saw redevelopment as a chance 'to set up a vibrant commercial/residential mix, climatically responsive and moulded to its site, of the kind for which there is no real precedent' (Farrelly, 1990). But, she said, this would require the government to set firm rules which could not be negotiated away by developers - a remit which had not been followed in the rest of Sydney and would not be in Pyrmont.

As development started, it was clear that the developer role in the planning process had not changed, and that the government's controls for its own dense vision were indeed being negotiated away. The problem was most evident on 'landmark' sites, but was also widespread outside those. As a result, Farrelly foresaw the re-emergence of sixties-style concrete blocks whose first two storeys would be 'dead' car parking space (Farrelly, 1993). This was supported by a study prepared by Professor Winston Barnett, who concluded that the proposed densities would require a built form 'totally unlike [Pyrmont's] historic form and more akin to high-density development in other parts of Asia' (O'Brien, 1993, p. 5A). The loss to new development of government land on the upper headland at Pyrmont Point, with its sweeping views along the harbour, was a particular concern. A rally of 'prominent people', including architects, and local residents was held to protest against the planned redevelopment (SMH 30 September 1995).

Planners in the city council, supported by the community independent Lord Mayor, began to raise their concerns. In 1993 a council planning paper warned against 'gargantuan, homogeneous projects' becoming the development norm (SMH 9 July 1996). Three years later in a report commissioned by the council, an urban designer reported on the reality of development in the interim. He said that the density, bulk, concentration and proximity of new residential development was 'producing an undesirable urban form inconsistent with the objectives of high quality design in the...regional...plan' with none of the desirable qualities of relaxation, calm, interaction, stimulation, pleasure and delight (SMH 9 July 1996). The council report which followed noted the main consequences of current planning controls. The 'excessive' eight to ten storey maximum building height 'closed out the sky' in narrow streets and dwarfed the original streetscapes. Inadequate massing of large residential developments created a dense environment akin to an industrial warehouse area. Development on landmark sites such as the Casino had inappropriate bulk (SMH 10 December 1996).

These concerns were brought home with development proposals for Pyrmont's main site, the old sugar refinery location. The master plan produced by the site's owners, the multinational financial conglomerate Lend Lease, substantially exceeded the development parameters set out in the regional plan. On the 'landmark' site of Distillery Hill, a 30-storey tower was proposed instead of the 21-storey building allowed in the plan. A zone of buildings to a maximum of 10 storeys in the regional plan was to have structures of 21, 18 and 13 storeys under the master plan. Another zone of 5 storeys in the regional plan included an 18-storey tower and adjacent buildings of 8 to 10 storeys in the master plan (SMH 16 May 1997). Overall, there was a great increase in dwelling density in the more profitable waterfront precincts compared with the regional plan, which envisaged a stepping down of heights to the harbour edge. The development application detailing the built form of the master plan had a hostile reception from professionals. The development proposed was seen by architects as 'really bad postmodernism', 'atrocious', 'boring', and generally failing to reinforce the site's rising topography, while only 'token' heritage buildings had been kept on a precinct rich in industrial history (Susskind, 1998). Today, a Gold Coast style strip is being built there on a site which was supposed to embody the best of the original urban village hopes (e.g. SMH 7 May 1996) for the peninsula's redevelopment.

When Pyrmont-Ultimo's days as a locus of heavy industry and freight transport came to an end, a constellation of opportunities for transforming the suburbs came into view. But the hopes of the community, environmentalists and urban designers for redevelopment which built on the existing urban fabric to create a living and working environment with a human scale and sensitivity to the local climate and topography have been largely dashed. The dominant habitus reflected in Pyrmont-Ultimo has arisen from an initial vision grounded in contemporary planning discourse and doctrine, reifying 
the compact city (Searle, 1999) and intensified by ideology requiring 'the highest and best use of a site' and by developers squeezing a discretionary planning system to maximise their profits. In the end it has been the high-density vision of developers which has prevailed, aided by a government ruled by an economic imperative to reduce its costs and maximise its revenues. Without an alternative habitus to replace that dominating contemporary planning, visions of a different kind of place seem destined to remain just visions.

\section{Pyrmont-Ultimo: some conclusions about 'the habitus' and habitués}

In many ways, the Australian experience is a mimesis of international redevelopments of waterfront exindustrial land, reproducing facsimiles of 'proven' developments in North America and Europe. The Pyrmont-Ultimo redevelopment is characteristic of the redevelopment of waterfront ex-industrial land throughout Australia in the 1990s, and indeed of similar developments in the United Kingdom and United States such as the Baltimore Inner Harbour and the London Docklands (Berry and Huxley, 1992; Holcomb, 1993). There are many common elements that these projects possess. The redevelopment of what was regarded as surplus government land through the appointment of specially created government instrumentalities using powerful, purpose-built, planning legislation, which was able to control the form, style and speed of redevelopment is emblematic. The ostensible exclusion of local government from most of the redevelopment planning and approval processes is also characteristic. State Governments regarding such land as "surplus" and "under-utilised”, and the nature of the land itself - old power station sites, railway yards and foundries, are other common features.

The fact that many such developments were touted as examples of urban consolidation and sustainability is also a commonality. Other trademark elements include: community opposition to the nature of the redevelopment; a lack of affordable housing (despite their being partly funded under the Building Better Cities programme); the redevelopment of public spaces (parks in particular) for private housing; the government view that the areas were "empty" prior to redevelopment; an emphasis on high technology industries within the developments; and a marked change in the social composition of the areas - from being formerly working class to being middle class and upper income following redevelopment. Sadly, rather than being innovative, sensitive and visionary the Pyrmont-Ultimo development had been "vision impaired" and characterised by a shift in place identity from industrial and working class to high-tech and upper income, from heterogeneous to homogeneous, from "derelict" to Disneyfied and ultimately from neighbourhood to commodity. Perhaps, as Podmore (1998) noted with 'loft living' in Montreal, this is no accident, and is instead indicative of a habitus at work, as these sites are converted into elitist exemplars of social practice, embodied in taste and lifestyle choices.

If any lesson is to be learned from this project, it is that planners cannot be relied upon to protect the interests of the marginalized and / or underrepresented, particularly in the provision or facilitation of the development of affordable housing and representing the interests of nature and non-human species. This may sound naïve, as it is perhaps 'commonsense', yet it is revealing precisely because of the habitus at work, one that conditions planners to view redevelopment outcomes as good and in the public interest. This habitus was at work in the redevelopment of low-income areas into parks under the reformist movement of the $19^{\text {th }}$ Century, and again in the conversion of inner-city neighbourhoods (slum clearance) into freeways and office space during the post Second World War urban renewal projects in North America, Europe and Australia.

The need for affordable housing, the pressures of the private market and the recovery of costs for largescale remediation of contaminated ex-industrial sites is a challenge that is yet to be adequately addressed by planners and government instrumentalities. It is a challenge that will be made all the more difficult by the fact that planners appear to be socially conditioned by pedagogy and praxis into perpetuating elitist models of development. This case study is a clear example of social exclusion and inequity present in inner city redevelopment projects in Australia - a fact that has not escaped other commentators. However, we believe that it demonstrates not only a lack of accountability in community consultation, a failure to use Federal money to provide affordable housing and a proclivity towards creating places for wealthy professional residents at the expense of existing residents, but most importantly, it casts serious doubts upon planners claims that they can balance competing interests. The case study demonstrates the need for continued research into the commodification of places, and especially into planners' roles as place entrepreneurs, in the political economy of place production. 


\section{Endnote}

SMH denotes Sydney Morning Herald

\section{References}

Alexander, I. (1994b) “Better Cities: for Whom?”, The Western Review, September, pp. 4.

Bell, K. (1993) Strategy for a Sustainable Sydney, Surry Hills NSW, Greenpeace Australia.

Berry, B. and Huxley, M. (1992) “ Big build: property capital, the state and urban change in Australia”, International Journal of Urban and Regional Research, Vol. 16(1), pp. 35 - 59.

Bourdieu, P. (1984) Distinction: A Social Critique of the Judgement of Taste, (trans. Richard Nice), Cambridge, Mass., Harvard University Press.

Bouveresse, J. (1999), “Rules, Dispositions and the Habitus”, in Shusterman, R. (ed.) Bourdieu: A Critical Reader, Oxford, Blackwell.

Brian Elton and Associates (1991) City West Urban Strategy Social Impact Assessment, Sydney, Department of Planning.

Butler, J. (1999) “Performativity’s Social Magic” in Shusterman, R. (ed.) Bourdieu: A Critical Reader, Oxford, Blackwell.

Chapman, R. (1999), “Settling Westchester: The Value of Place” Capitalism, Nature, Socialism, Vol. 10(3), pp. 81-88.

City West Development Corporation (1998) City West Urban Renewal Six Years On, Sydney, CWDC.

Cosgrove, D. (2000), "Sense of Place”, in Johnston, R.J., Gregory, D., Pratt, G. and Watts, M. (eds.) The Dictionary of Human Geography $4^{\text {th }}$ edn., Oxford, Blackwell.

Davis, M. (1992) City of Quartz, New York, Vintage Books.

Department of Planning (1990) City West Urban Strategy: Planning Opportunities, Sydney, Department of Planning.

Department of Planning (1991) City West Draft Regional Environmental Plan No. 26 and Draft Urban Development Plan, Sydney, Department of Planning.

Duany, A. and Plater-Zyberk, E. (1991) Towns and town-making principles, New York, Rizzoli.

Farrelly, E. M. (1990) "Why Sydney Finds It Hard to Shape Up”, Sydney Morning Herald, 7 November, p. 15.

Farrelly, E. M. (1993) “Concrete Blocks on the Rise Again”, Sydney Morning Herald, 1 December, p. 15.

Fitzgerald, S and Golder, H. (1994) Pyrmont and Ultimo under Siege, Sydney, Hale and Iremonger.

Harvey, D.C. (2000), “Landscape Organization, Identity and Change: territoriality and hagiography in medieval west Cornwall”, Landscape Research, Vol. 25(2), pp. 201-212.

Healey, P. (2000), “Connected Cities”, Town and Country Planning, Feb. , pp. 55-57.

Hillier, J. and Searle, G. (1995) "Rien Ne Va Plus: Fast Track Development and Public Participation in Pyrmont-Ultimo, Sydney”, Sydney Vision: UTS Papers in Planning Number 3, Planning Program, Faculty of Design, Architecture and Building, University of Technology, Sydney. 
Hillier, J. (2001a) “Mind the Gap” in Hillier, J. and Rooksby, E. (eds.) Habitus: A Sense of Place, Ashgate, Aldershot.

Hillier, J. (2001b) “'Practical Action, Political Vision’: Planners as Missionaries or Chameleons?”, paper presented to the World Planning Schools Congress, Tongji University, Shanghai, 11 15 July, 2001.

Holcomb, B. (1993), “Revisioning Place: De- and Re-constructing the Image of the Industrial City” in Kearns, G. and Philo, C. (eds.) Selling Places: The City as Cultural Capital, Past and Present, Oxford, Pergamon Press.

King, M. and Cavadini, F. (1994) Concrete City, Videorecording, Sydney, Frontyard Films.

Logan, J.R. and Molotch, H.L. (1987) Urban Fortunes: The Political Economy of Place, Los Angeles, University of California Press.

Lowe, M. (1993), “Local Hero! An Examination of the Role of the Regional Entrepreneur in the Regeneration of Britain’s Regions” in Kearns, G. and Philo, C. (eds.) Selling Places: The City as Cultural Capital, Past and Present, Oxford, Pergamon Press.

O’Brien, G. (1993) "Pyrmont: Blurring the Vision Splendid”, Sydney Morning Herald, 18 December, p. 5 A.

O’Brien, G. (1994) “Filmed: The Dying of Pyrmont’, Sydney Morning Herald, 26 June, p. 24.

Philo, C. and Kearns, G (1993) "Culture, History, Capital: A Critical Introduction to the Selling of Places”, in Kearns, G. and Philo, C. (eds.) Selling Places: The City as Cultural Capital, Past and Present, Oxford, Pergamon Press.

Podmore, J. (1998) “(Re)reading the 'loft living' habitus in Montreal's inner city”, International Journal of Urban and Regional Research, Vol. 22(2), pp. 283-302.

Searle, G. (1998) “How Green is Urban Consolidation?”, Architecture Bulletin, No. 9, p. 16.

Searle, G. (1999) "Planning doctrine and the persistence of Sydney's urban consolidation strategy", Congress Papers, Royal Australian Planning Institute $27^{\text {th }}$ National Congress, $19-22$ September 1999, http//www.lpe.nt.gov.au/devel/planning/rapi/default.htm.

Searle, G. and Bounds, M. (1999) "State Powers, State Land and Competition for Global Entertainment: The Case of Sydney”, International Journal for Urban and Regional Research, Vol. 23, pp. 165-172.

Smith, N. (1996) The New Urban Frontier: Gentrification and the Revanchist City, London, Routledge.

Stephens, J. (1997) Memorandum regarding the habitus question, pers. com.

Susskind, A. (1998) “\$800m Jacksons Landing -“another harbourside embarrassment’ ”, Sydney Morning Herald, 10 August, p. 6.

Travis Partners (1991) Ultimo-Pyrmont Planning Study, Sydney, Department of Planning.

Wallace, R.A. and Wolf, A., (1995), Contemporary Sociological Theory: Continuing the Classical Tradition, Englewood Cliffs, Prentice Hall. 